Biosystems Engineering (2004) 87(4), 387-392

doi:10.1016/j.biosystemseng.2004.01.004

PA-Precision Agriculture
Available online at www.sciencedirect.com

science@Direct

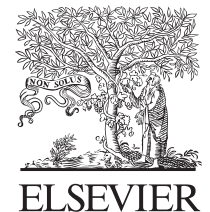

\title{
Spatially Variable Rate Herbicide Application on Durum Wheat in Sicily
}

\author{
M. Carrara; A. Comparetti; P. Febo; S. Orlando \\ Dipartimento di Ingegneria e Tecnologie Agro-Forestali (I.T.A.F.), Università di Palermo, Viale delle Scienze, 13-90128 Palermo, Italy; \\ e-mail of corresponding author: comparetti@unipa.it
}

(Received 8 May 2003; accepted in revised form 26 January 2004)

Using the conventional farming system, durum wheat requires high rates of herbicide spraying. Herbicide residues can cause pollution of soil and ground water and, therefore, of the entire environment.

In order to minimise the environmental impact of herbicides, a home-made system for spatially variable rate crop input application was designed and developed. This system consists of a differential global positioning system (DGPS), a portable computer, specifically developed software and a device for applying rates proportionally related to the machine forward speed.

Tests of spatially variable rate herbicide application were carried out in inland Sicily, on a field of 8.4 ha (where a 3-yr crop rotation of broad bean/vetch, durum wheat and durum wheat was practised), using a sprayer modified for applying variable rates and equipped with the above-mentioned system.

The results are promising. The spatially variable rate herbicide application allowed an almost even grain yield over the entire field and a saving of $29 \%$ of herbicides with respect to the amounts normally used with the conventional farming system.

(C) 2004 Silsoe Research Institute. All rights reserved

Published by Elsevier Ltd

\section{Introduction}

Durum wheat is one of the most commonly cultivated crops in Sicily, where in the year 2000, it was cultivated on 333435 ha (equal to the $20 \%$ of the Italian durum wheat surface). At that time Sicily had a grain production of $818540 \mathrm{t}$, equal to the $18 \%$ of the Italian production (ISTAT, 2001).

Using the conventional farming system, durum wheat requires the spraying of a high quantity of herbicides with the same amount all over the field, in order to control monocotyledonous and dicotyledonous weeds, such as Avena fatua L., Lolium perenne L., Phalaris spp. L. and Galium aparine L.

The following herbicides are normally mixed and sprayed together: $0 \cdot 25 \mathrm{lha}^{-1}$ of Topik (in liquid form) with its active ingredient (Clodinafop) acting on monocotyledonous weeds, such as Avena fatua $L$., Lolium perenne $L$. and Phalaris spp. L.; $37 \mathrm{gha}^{-1}$ of Logran (in granular form) with active ingredient (Triasulfuron) acting on dicotyledonous weeds, such as Galium aparine L.; $15 \mathrm{~g} \mathrm{ha}^{-1}$ of Pointer (in granular form) with its active principle (Tribenuron metile) acting on dicotyledonous weeds; $2 \cdot 5-3 / \mathrm{ha}^{-1}$ of Dicuran 700 FW (in liquid form) with its active ingredient (Chlorotoluron) acting on monocotyledonous and dicotyledonous weeds; and 3.5-5 $l \mathrm{ha}^{-1}$ of Zodiac Dicuran DFF (in liquid form) with its active ingredients (Chlorotoluron and Diflufenican) acting on monocotyledonous weeds, such as Lolium perenne L., and most dicotyledonous weeds.

The period for achieving the best response to herbicide spraying is when the weeds are in active growth (bunching and rising phenological phases). Herbicide residues can cause pollution of soil and ground water and, therefore, of the entire environment (Comparetti et al., 2001).

The distribution of grass weeds in cereal crops is usually patchy. Weed patches are relatively stable over a number of growing seasons (Miller et al., 1995), and weeds such as wild oats (Avena fatua $L$.) could cause a $2 \%$ yield loss in cereal crops even at densities as low as one to two plants per square meter (Wilson \& Brain, 1990).

The targeting of herbicides to grass weed patches in cereal crops may lead to reductions in herbicide 
amounts of $40-60 \%$, depending on the weed patch distribution within the field (Stafford \& Miller, 1996). The consequences, both in terms of economical benefits and environmental protection, are evident.

Two methods of herbicide application in cereal fields, both different from the conventional even rate spraying, were investigated. The first consists of an 'on/off' herbicide application, the second applies the principles of precision agriculture and consists of a spatially variable rate herbicide application.

\section{Materials and methods}

The tests were carried out in inland Sicily, on a field of 8.4 ha, with a clay soil texture and where a 3-yr crop rotation (broad bean/vetch, durum wheat, durum wheat) was practised.

For both methods of herbicide application used in the comparison an herbicide mixture with a concentration of $0.001 l$ of Topik $240 \mathrm{EC}$ and $0.06 \mathrm{~g}$ of Pointer per litre was applied.

The weed distribution was monitored in February 2000. The main weed species, in competition with durum wheat, were Lolium perenne L. and Phalaris spp. L., while the presence of other weed species, such as Avena fatua L., Galium aparine L., Sinapis nigra L. and Soncus spp. L., was negligible. Two areas, with respectively high and low weed density, were observed in the field.

The boundaries of the whole field and of the high and low weed density areas (of 3.6 and 4.8 ha, respectively) were mapped, using a differential global positioning system (DGPS), DSNP Scorpio 6502 SK/MK.

In March, an 'on/off' herbicide application was carried out, using this DGPS. A herbicide mixture rate of $250 l \mathrm{ha}^{-1}$ was applied over the high weed density area ('on' area), while no herbicide at all was applied over the rest of the field ('off' area).

A total of $0.9 l$ of Topik $240 \mathrm{EC}$ and of $54 \mathrm{~g}$ of Pointer was applied over the 'on' area of 3.6 ha, using a sprayer with a tank of $400 l$ capacity and a $10 \mathrm{~m}$ wide boom with 20 nozzles. Figure 1 shows the 'on/off' herbicide application map.

In July, the cereal crop was harvested separately over the 'on' and 'off' areas, using a combine harvester equipped with the DGPS and a portable computer that could display the machine real time position on the field map (Fig. 2).

In order to carry out the spatially variable rate herbicide application in the following year, a system for variable rate crop input application was designed, developed and set up by the Department of Engineering and Technologies in Agriculture and Forestry (ITAF). This system was compatible with most positioning

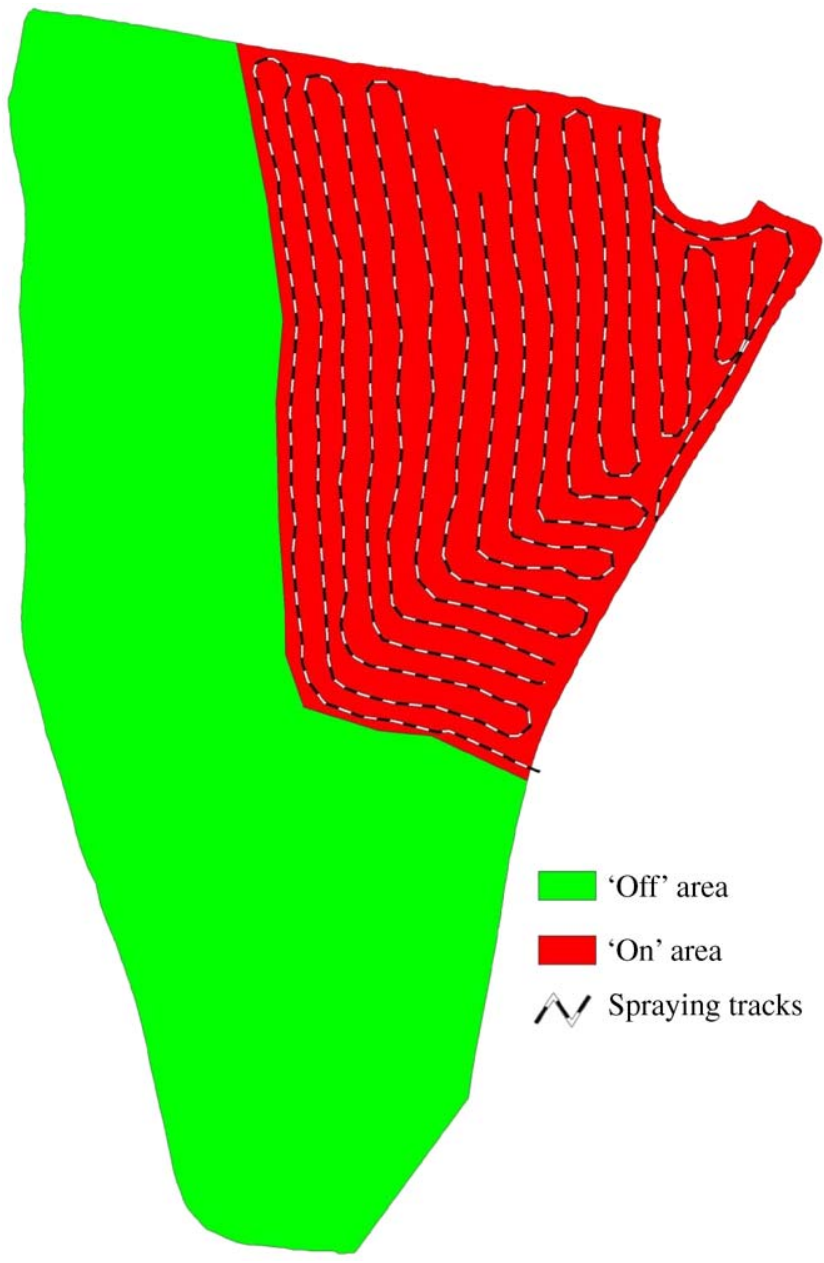

Fig. 1. 'On/off' herbicide application map

systems and sprayers able to apply rates proportionally related to the machine forward speed. It consisted of the DGPS, a portable computer, specifically developed software called Precision Agriculture Controller (PAC) and a system able to apply rates proportionally related to the machine forward speed, comprising data sensing and processing and an active system (Fig. 3).

The custom-built portable computer had two RS232 serial ports, for receiving the machine position from the DGPS mobile receiver and for transmitting the rate to be applied to the active system.

The software task was to: receive and interpret the DGPS position data and compare them with the application map; transmit commands to the active system; log the spraying tracks and the applied rates.

The data sensing system comprised a pressure transducer, mounted on the boom, and a Doppler radar, mounted on the left side of the tractor gear box.

Sensing the machine forward speed and the liquid pressure in the hydraulic circuit, the data processing system computed the rate to be applied, in $l \mathrm{ha}^{-1}$, 


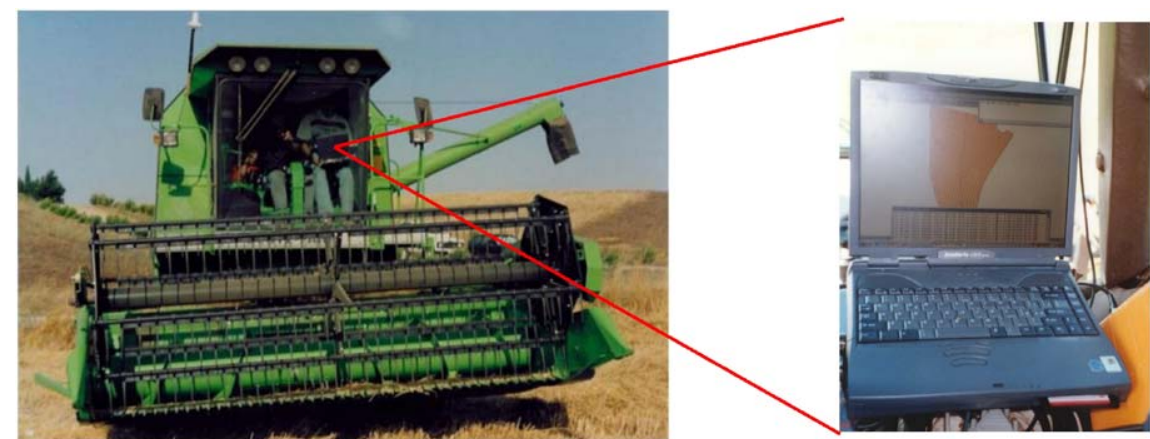

Fig. 2. Combine harvester equipped with differential global positioning system (DGPS) and portable computer, for displaying the real time position of the machine on the field map

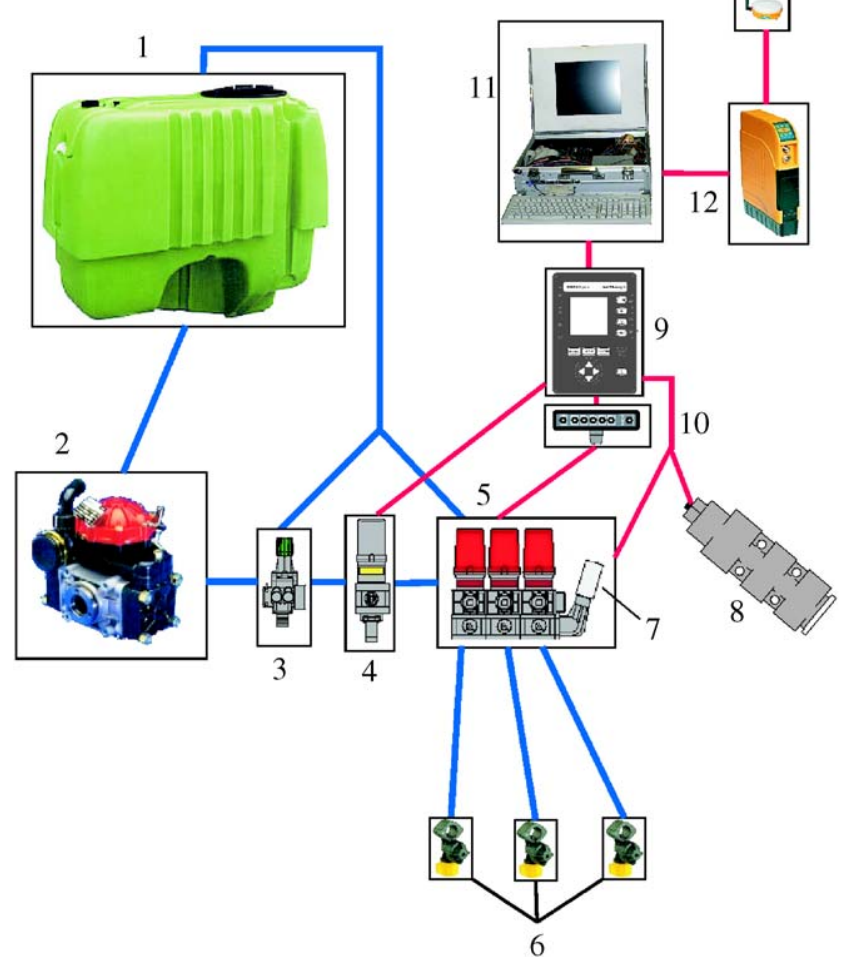

Fig. 3. Main components of the system for the spatially variable rate herbicide application: (1) tank; (2) pump; (3) pressure regulator; (4) pressure-regulating valve, moved by stepper motor; (5) section electrovalves; (6) boom sections; (7) pressure transducer; (8) Doppler radar; (9) Land Manager; (10) boom section switches; (11) portable computer; (12) differential global positioning system (DGPS) mobile receiver; (13) global positioning system (GPS) antenna and ultra-high frequency (UHF) radio antenna; —, hydraulic circuit; - , cables

according to the working width and the technical specifications of hydraulic circuit and nozzles. The data processing system could be remotely controlled by a computer, through an RS232 serial interface, in order to

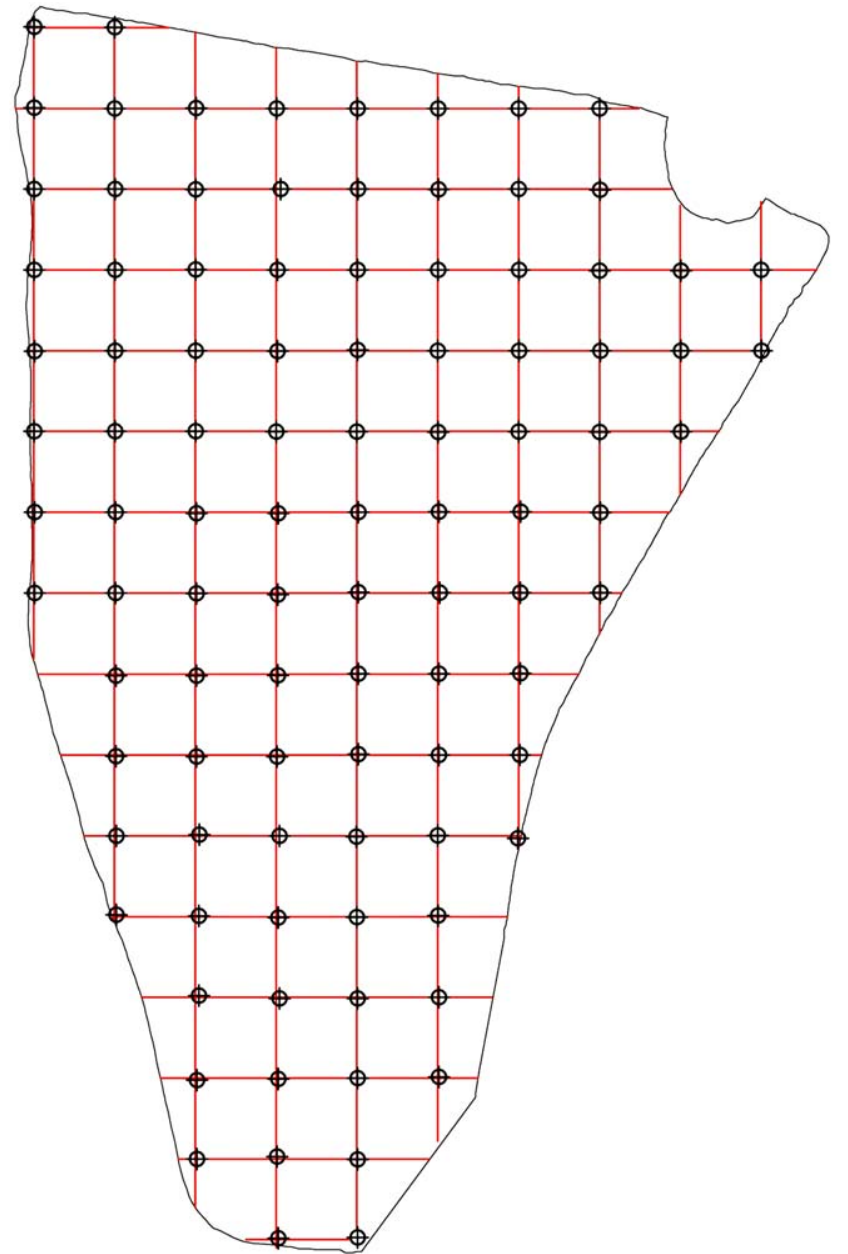

Fig. 4. Grid overlaid on the field map for identifying the circular areas where weeds were monitored

change the parameters of the sprayer and/or the rate to be applied.

The active system comprised a pressure-regulating valve, moved by a stepper motor. 


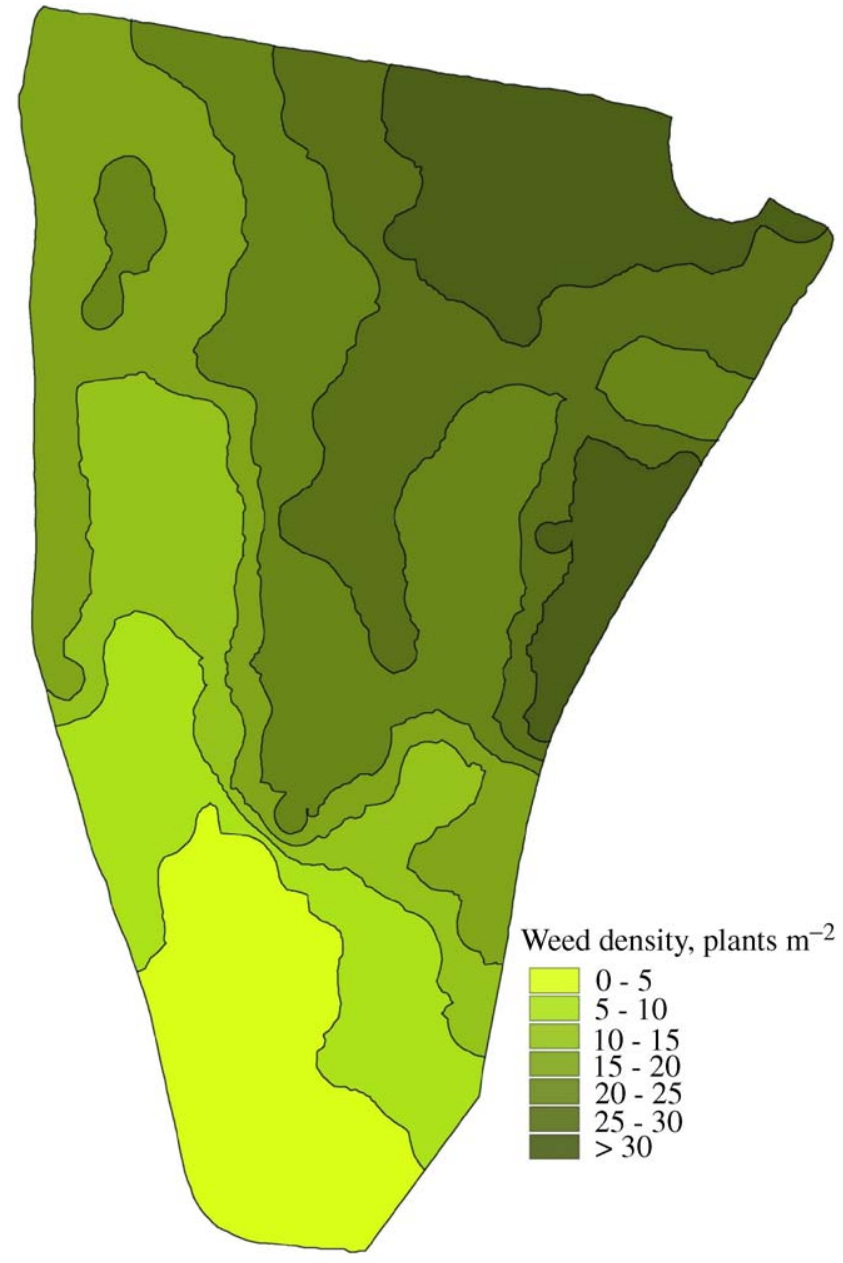

Fig. 5. Weed distribution map, obtained interpolating linearly the weed densities measured in the vertices of the grid cells

In order to apply the previously selected rate, the data processing system transmitted the input to this motor, which regulated the valve opening and, therefore, the pressure of the hydraulic circuit. When the machine forward speed and/or the liquid pressure changed, the data processing system transmitted the corresponding input to the active system, which varied the valve opening accordingly (Carrara et al., 2001; Comparetti \& Orlando, 2001).

In 2001 the weed distribution of the test field was mapped, using a grid with cells of 25 per $25 \mathrm{~m}$, in 99 circular areas of $1 \mathrm{~m}^{2}$, placed on the vertices of the cells (Fig. 4).

Weed densities (plants $\mathrm{m}^{-2}$ ) and their positions in the durum wheat field were processed with a commercial software. The weed densities were linearly interpolated in the vertices of the grid cells. The result was a weed distribution map (Fig. 5), where seven areas, each representing a different weed density, were identified.

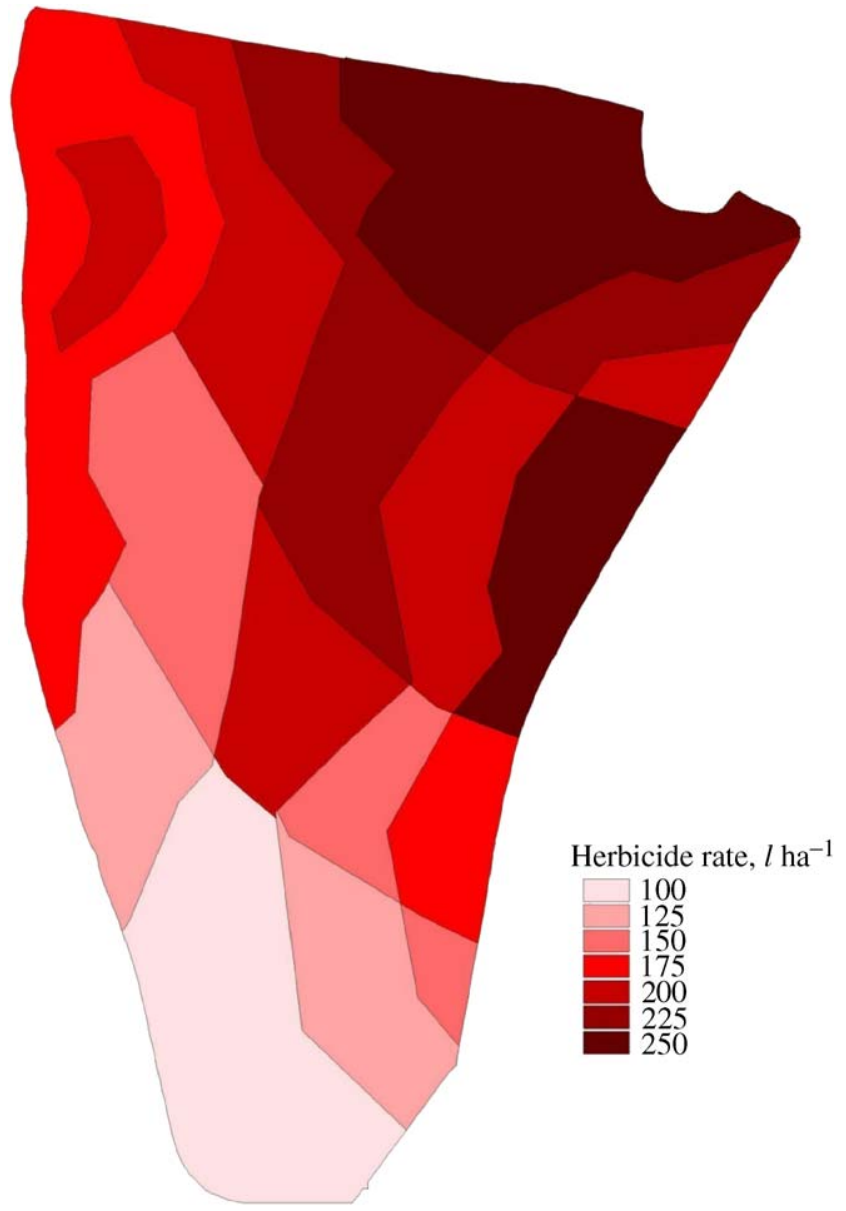

Fig. 6. Herbicide rate application map

A specific herbicide rate was decided for each weed density, in order to produce the herbicide application map (Fig. 6), which was logged onto the portable computer of the system.

The tests of spatially variable rate herbicide application were carried out in March, using the same sprayer as the previous year, suitably modified for applying variable rates of herbicides and equipped with the above mentioned system. The boom was divided into three sections, each equipped with an electrovalve and seven nozzles (Fig. 7).

In order to produce the map of the herbicide applied rates (Fig. 8), the PAC software logged the boom width, the spraying tracks and the rates applied (variable from 100 to $250 l \mathrm{ha}^{-1}$ ).

The same herbicides as the previous year were used for preparing the mixture. A total of $1500 l$ of water, mixed with $1.5 \mathrm{l}$ of Topik and $90 \mathrm{~g}$ of Pointer, was applied over the entire field.

In July 2001, the cereal crop was harvested separately over the areas called 'on' and 'off' in the previous year. 


\section{Results and discussion}

In the first year, when the 'on/off' herbicide application was carried out, the grain yield was $6 \cdot 3 \mathrm{tha}^{-1}$ in the 'on' area and $4.5 \mathrm{tha}^{-1}$ in the 'off' area, where the weed density was recorded as negligible. The yield difference of $1.8 \mathrm{tha}^{-1}$ demonstrates the usefulness of the herbicide application.

In the second year, when the spatially variable rate herbicide application was carried out (over the entire field), the average grain yield was of $4.2 \mathrm{tha}^{-1}$ in the 'on' area and $4.1 \mathrm{tha}^{-1}$ in the 'off' area; 33 and $9 \%$, respectively, lower than the previous year. The yield reduction was, however, expected because: (a) it was the second year of durum wheat cultivation in the field; and (b) unfavourable climatic conditions caused a yield reduction over the entire region.

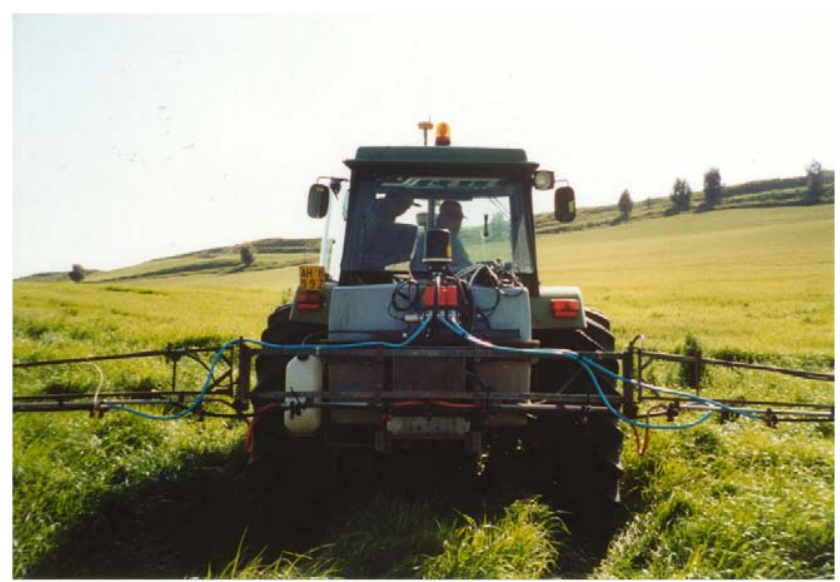

Fig. 7. Rear view of the tractor and modified boom, used for the spatially variable rate herbicide application
However, the grain yield was almost even over the entire field, demonstrating that the spatially variable rate herbicide application was effective.

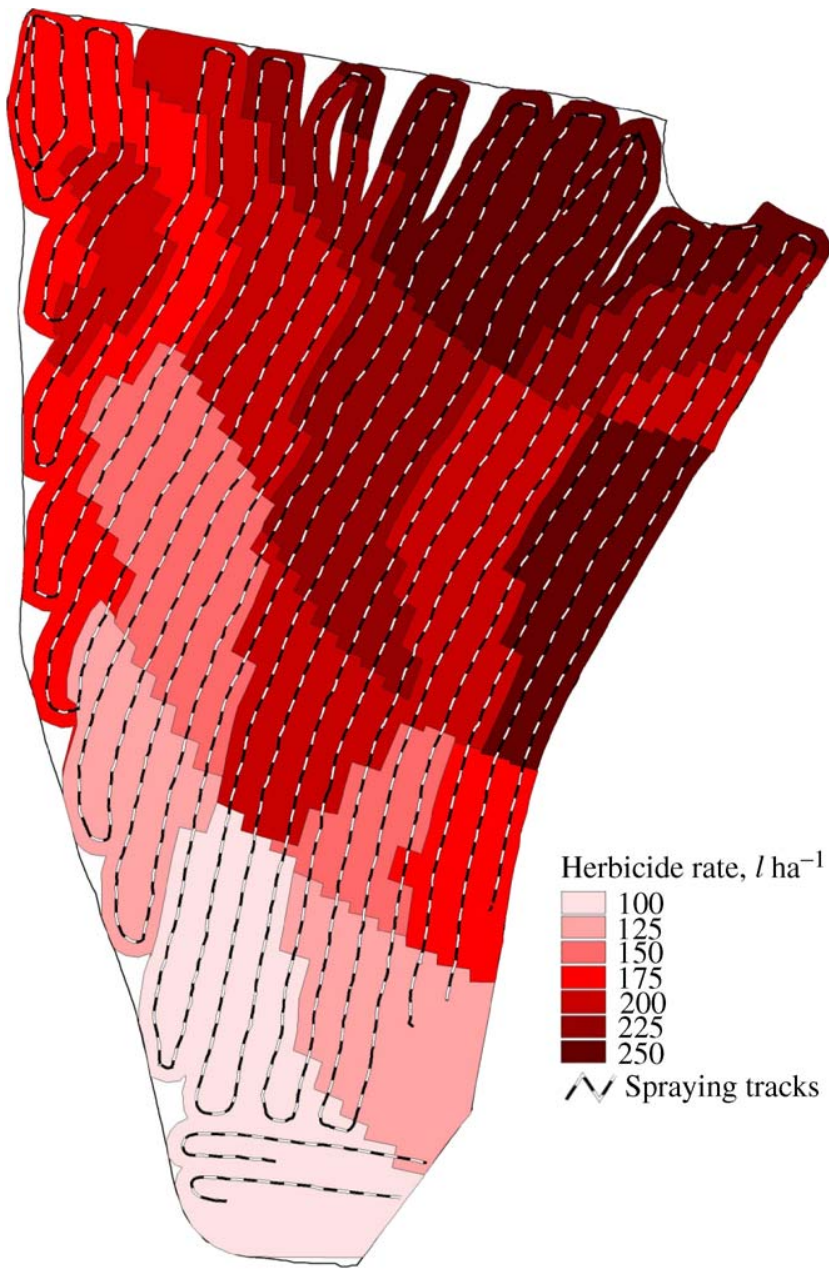

Fig. 8. Actual spatially variable rate herbicide application map

Table 1

Treated areas, herbicide mixture rates and volumes, herbicide quantities and savings of the spatially variable herbicide application method with respect to the conventional one

\begin{tabular}{|c|c|c|c|c|c|}
\hline Herbicide application method & Surface, ha & Herbicide mixture, lha $^{-1}$ & Herbicide mixture, $l$ & Topik, l & Pointer, $g$ \\
\hline Conventional & $8 \cdot 40$ & 250 & $2100 \cdot 00$ & $2 \cdot 10$ & $126 \cdot 00$ \\
\hline \multirow[t]{2}{*}{ 'On/off' } & 3.60 ('On’) & 250 & $900 \cdot 00$ & 0.90 & 54.00 \\
\hline & $4 \cdot 80$ ('Off') & 0 & 0 & 0 & 0 \\
\hline \multirow[t]{7}{*}{ Spatially variable } & 0.92 & 100 & $92 \cdot 00$ & 0.09 & $5 \cdot 52$ \\
\hline & 0.89 & 125 & 111.25 & $0 \cdot 11$ & $6 \cdot 68$ \\
\hline & $0 \cdot 86$ & 150 & $129 \cdot 00$ & $0 \cdot 13$ & 7.74 \\
\hline & $1 \cdot 14$ & 175 & $199 \cdot 50$ & $0 \cdot 20$ & 11.97 \\
\hline & $1 \cdot 82$ & 200 & 364.00 & $0 \cdot 36$ & $21 \cdot 84$ \\
\hline & $1 \cdot 14$ & 225 & $256 \cdot 50$ & $0 \cdot 26$ & $15 \cdot 39$ \\
\hline & $1 \cdot 39$ & 250 & $347 \cdot 50$ & $0 \cdot 35$ & $20 \cdot 85$ \\
\hline Total & $8 \cdot 16$ & - & $1500 \cdot 00$ & 1.50 & 89.99 \\
\hline Saved quantity & & & $600 \cdot 00$ & $0 \cdot 60$ & $36 \cdot 02$ \\
\hline Saving, $\%$ & & & 28.57 & $28 \cdot 57$ & $28 \cdot 57$ \\
\hline
\end{tabular}


Moreover, only $0 \cdot 18 \mathrm{lha}$ of Topik and $11 \mathrm{gha}^{-1}$ of Pointer were applied, allowing a saving of $600 l$ of herbicide mixture (corresponding to a saving of $71 / \mathrm{ha}^{-1}$ ) with respect to the amount normally used with the conventional farming system (Table 1).

\section{Conclusions}

The tests showed that, despite the significant variability of weed distribution and density monitored in the field, the spatially variable rate herbicide application was effective, allowing an almost even grain yield over the entire field and, at the same time, reducing the environmental impact due to herbicide residues.

In fact, a saving of approximately $29 \%$ of herbicides was recorded with respect to the amounts normally used with the conventional farming system.

\section{References}

Carrara M; Comparetti A; Orlando S (2001). Un sistema innovativo applicabile all'agricoltura di precisione. [A modern system for precision agriculture.] Convegno AIIA
'Ingegneria Agraria per lo Sviluppo dei Paesi del Mediterraneo', Vieste del Gargano (Foggia), Italy, 11-13 September

Comparetti A; Orlando S (2001). A home made system for precision agriculture. First tests of variable rate herbicide application. Third European Conference on Precision Agriculture, Montpellier, France, 18-20 June

Comparetti A; Febo P; Morello G; Orlando S (2001). Prove di diserbo spazialmente variabile in un'azienda cerealicola siciliana. [Tests of spatially variable rate herbicide application in a Sicilian cereal farm.] Convegno AIIA 'Ingegneria Agraria per lo Sviluppo dei Paesi del Mediterraneo', Vieste del Gargano (Foggia), Italy, 11-13 September

ISTAT (2001). Coltivazioni: dati congiunturali-Coltivazioni 2000. [Crops: short-term data-Crops 2000.] Istituto Nazionale di Statistica. URL: http://www.istat.it/

Miller P C H; Stafford J V; Paice M E R; Rew L J (1995). The patch spraying of herbicides in arable crops. Brighton Crop Protection Conference-Weeds-1995, pp. 1077-1086, UK

Stafford J V; Miller P C H (1996). Spatially variable treatment of weed patches. Third International Conference on Precision Agriculture, Minneapolis, Minnesota, USA, 23-26 June

Wilson B J; Brain P (1990). Weed monitoring on a whole farm-patchiness and the stability of distribution of Alopecurus myosuroides over a ten year period. Proceedings of European Weed Society Symposium-Integrated Weed Management in Cereals, pp. 47-52, Helsinki, Finland 